\section{Detection of Egg and Milk Residues on Work Surfaces in School Canteens in the Hortaleza District, Madrid and Their Relevance to Children With Allergy to These Food Groups}

Ortiz-Menéndez $\mathrm{JC}^{1}$, Cabrera $\mathrm{M}^{2}$, Mateos Alonso $\mathrm{A}^{3}$, García Álvarez $\mathrm{M}^{3}$, Ortiz Ramos $\mathrm{M}^{3}$, Garzón $\mathrm{B}^{4}$, Galán-Malo $\mathrm{P}^{5}$, Mata L ${ }^{5}$ ${ }^{I}$ Departamento de Sanidad, Distrito de Hortaleza, Ayuntamiento de Madrid, I'MFINE Research Group, Madrid, Spain

${ }^{2}$ Servicio de Alergia, Hospital los Madroños, Brunete (Madrid), Spain

${ }^{3}$ Departamento de Servicios Sanitarios, Calidad y Consumo, Distrito de Hortaleza, Ayuntamiento de Madrid, Madrid, Spain

${ }^{4}$ Unidad de Estadistica, Secretaría Adjunta de Informática, Consejo Superior de Investigaciones Cientificas (CSIC), Madrid, Spain

${ }^{5}$ Laboratorios Zeulab, Zaragoza, Spain

J Investig Allergol Clin Immunol 2019; Vol. 29(1): 70-71 doi: $10.18176 /$ jiaci.0336

Key words: Food allergy. School canteens. Food traces. Milk. Egg. ELISA. LFIA.

Palabras clave: Alergia a alimentos. Comedores escolares. Trazas de alimentos. Leche. Huevo. ELISA. LFIA.

There is growing awareness of allergen management in catering companies, including those that supply school canteens, as trace amounts of allergenic foods can trigger an allergic reaction [1-2].

A survey of management programs and control of special diets for food allergy in 48 schools in the Hortaleza District of Madrid, Spain (all of them self-catering) was performed during the 2015-2016 school year. Of a total of 1509 served meals, 361 were free of egg and milk allergens.
The aim of this study was to perform immunoassays on a sample of allergens on working surfaces, utensils, and dishes in school kitchens in order to detect milk and egg allergens. We then evaluated the impact on children sensitized to the allergens in terms of the prevalence of allergy to these foods and how they may be related to reactive episodes after inadvertent intake.

Samples were collected by a single technician, who swabbed work surfaces. The samples were then analyzed using lateral flow immunoassay (LFIA, Proteon Milk Express and Proteon Egg Express from ZEULAB, S.L.) and enzyme-linked immunosorbent assay (ELISA, Proteon Milk and Proteon Egg from ZEULAB, S.L.), which were performed following the manufacturer's instructions. The recovery and reproducibility of both methods were previously validated for 2 types of surfaces: stainless steel and formica [3]. In each, at least 2 clean containers or utensils were randomly selected for the analysis of egg and milk residues (213 samples for both milk and egg). The surfaces were randomly selected and included 116 and 90 surfaces for exclusive use in the preparation of meals free of egg and milk allergens, respectively. In 7 cases, the food allergen-free diets were cooked before other meals. Briefly, swabs provided with the kits were dipped into the analysis buffer before being applied to the surfaces. Although allergen risk management guidelines usually recommend swabbing a working surface of at least $100 \mathrm{~cm}^{2}$, for practical reasons, we swabbed the whole food contact surface of each utensil. We used nominal variables, ie, presence and absence of food allergens (dummy), to investigate potential relationships between them $\left(\chi^{2}\right.$ test, $\left.P<.05\right)$.

During this school year, egg-free and milk-free diets were provided for children whose food allergies were confirmed by a specialist. Reactions occurring during the study period in this group of children were also recorded.

Egg and milk were detected using ELISA at low levels: 0.04 and $0.2 \mu \mathrm{g}$, respectively. However, the level of detection with LFIA increased to $0.07 \mu \mathrm{g}$ for egg and $0.6 \mu \mathrm{g}$ for milk, depending on the type of surface. The frequency of diets free of egg and milk in this group of children was $23.46 \%$ and $8.80 \%$, respectively ( $4.25 \%$ for both food allergies).

Table. Relationship Between Egg Allergy Events and Finding of Egg on Working Surfaces ${ }^{\mathrm{a}}$

\begin{tabular}{|c|c|c|c|c|}
\hline & & \multicolumn{2}{|c|}{ Egg LFIA results } & \multirow[b]{2}{*}{ Total } \\
\hline & & Negative & Positive & \\
\hline \multicolumn{5}{|c|}{2015 FA Events } \\
\hline \multirow{3}{*}{ Negative } & $\mathrm{n}$ & 27 & 6 & 33 \\
\hline & $\% 2015$ FA events & 81.8 & 18.2 & 100.0 \\
\hline & \% Results Egg LFIA & 79.4 & 46.2 & 70.2 \\
\hline \multirow[t]{3}{*}{ Positive } & $\% 2015$ FA events & 50.0 & 50.0 & 100.0 \\
\hline & \% Results Egg LFIA & 20.6 & 53.8 & 29.8 \\
\hline & $\mathrm{n}$ & 34 & 13 & 47 \\
\hline \multirow[t]{2}{*}{ Total } & $\% 2015$ FA events & 72.3 & 27.7 & 100.0 \\
\hline & \% Results Egg LFIA & 100.0 & 100.0 & 100.0 \\
\hline
\end{tabular}

Abbreviations: FA, food allergy; LFIA, lateral flow immunoassay.

${ }^{a} \chi^{2}$ statistic: $4.974(P=.026)$. 
No significant relationship was found between schools with children who had egg and milk allergy and the respective positive results (11 and 4 schools by LFIA and 21 and 2 by ELISA, respectively).

The levels of detection with ELISA are lower than with LFIA owing to the characteristics of the techniques themselves. Although we found that ELISA detected lower levels of milk and egg residues with respect to the LFIA, it did not significantly affect the proportion of positive results found in the study. However, in schools where events occurred, there was a significant relationship between episodes of food reaction (not requiring epinephrine) and positive egg allergy results by LFIA $\left(P=.026, \chi^{2} ; 14\right.$ positive episodes with 7 positive traces vs 33 negative episodes with 27 negative traces) (Table) [3].

The allergic-positive and nonallergic-negative association does not become significant, because the sample sizes in both cases are not sufficiently different. In other words, the positive results obtained are not significantly related to the fact of being allergic. Levels of detection with ELISA are lower than with LFIA owing to the characteristics of the techniques themselves. Although ELISA does detect lower levels of milk and egg residues than LFIA, it does not significantly affect the proportion of positives found in the study.

Seven, 4, and 3 of these reactions occurred in children sensitized to egg, milk, and both allergens, respectively. As for causes, we think that the reactions were due to foods that did not contain egg or milk and in which it can be assumed that there could be food contaminated by the traces present in the kitchens. Previous studies show that milk was the most frequent cause of anaphylaxis (43\%-53\%) [4-5], especially during the first years of life [4-6]. We previously reported a prevalence of diets free of egg and milk allergens of $32.78 \%$ and $17.08 \%$, respectively, in this school district [1]. Several studies suggest that the diagnosis of asthma is a risk factor for the occurrence of severe, potentially fatal anaphylactic reactions to food [7].

The high frequency of anaphylaxis caused by accidental exposure, in restaurants, during recreational activities, and at school and starting within 30 minutes of contact, as well as the high number of recurrences $[4,5,7]$, emphasizes the importance of training teachers, catering professionals, and the general public to identify the reactions rapidly and act accordingly.

Although epinephrine is recommended as first-line treatment in anaphylaxis consensus statements and guidelines [6,8], and nonuse or delayed administration is a risk factor for biphasic, more severe anaphylactic reactions and death [8], it remains underused in the emergency department.

Special care must be taken in the preparation of allergen-free diets to prevent cross-contamination. The presence of egg traces in the school kitchens may have contributed to the appearance of these reactions. Strict controls are needed to guarantee correct manipulation and, therefore, greater safety with the aim of preventing food allergy episodes in schools. In fact, in Hortaleza district, measures related to food safety information, training, and control have been in place since 2009.

\section{Acknowledgments}

We thank all of the families and school staff who made this project possible.

\section{Funding}

The authors declare that no funding was received for the present study.

\section{Conflicts of Interest}

The authors declare that they have no conflicts of interest.

\section{Previous Presentations}

The study was presented at the 2017 Congress of the European Academy of Allergy and Clinical Immunology, $17-$ 21 June 2017, Helsinki, Finland.

\section{References}

1. Cabrera M. Ortiz-Menéndez JC. López-Gay D. Prevalence of food allergen-free diets in school canteens in Hortaleza district. Madrid. Pediatr Allergy Immunol. 2014 Nov; 25(7):719-21.

2. Cabrera M, Ortiz-Menéndez JC, Garzón B, Barrios L. Need for Emergency Epinephrine to Treat Food Allergy Reactions in Schools in the Hortaleza District in Madrid. J Investig Allergol Clin Immunol. 2017;27(1):58-60.

3. Galan-Malo P, López M, Ortiz, JC, Pérez MD, Sánchez $L$, Razquin $P$, Mata L. Detection of egg and milk residues on working surfaces by ELISA and lateral flow immunoassay tests. Food Control. 2017;74:45-53.

4. Morais-Almeida M, Gaspar A, Santa-Marta C, Piedade S, Leiria-Pinto P, Pires $G$, et al. Anafilaxia - Da notificação e reconhecimento à abordagem terapêutica. Rev Port Imunoalergologia. 2007;15:19-41.

5. Silva R, Gomes E, Cunha L, Falcao H. Anaphylaxis in children: a nine years retrospective study (2001-2009). Allergol Immunopathol (Madr). 2012;40:31-6.

6. Grabenhenrich I, Dölle S, Moneret-Vautrin A, Köhli A, Lange L, Spindler T, et al. Anaphylaxis in children and adolescents: The European Anaphylaxis Registry. Volume 137, Issue 4, Pages 1128-37.e1.

7. Muraro A, Roberts G, Worm M, Bilò MB, Brockow K, Fernández Rivas $M$, et al. Anaphylaxis: guidelines from the European Academy of Allergy and Clinical Immunology. Allergy. 2014;69:1026-45.

8. Lieberman P, Nicklas RA, Oppenheimer J, Kemp SF, Lang DM, Bernstein DI, et al. The diagnosis and management of anaphylaxis practice parameter: 2010 update. J Allergy Clin Immunol. 2010;126:477-80.e1-42.

9. Sheikh A, Shehata YA, Brown SG, Simons FE. Adrenaline for the treatment of anaphylaxis: Cochrane systematic review. Allergy. 2009;64:204-12.

- Manuscript received August 17, 2018; accepted for publication October 8, 2018.

Martha Cabrera Sierra Servicio de Alergia. Hospital los Madroños Carretera M-501, Km 17,9 28690 Brunete, Madrid E-mail: marthacs65@gmail.com 